\title{
ELECTRONIC MAIL COMPETITIONS
}

\author{
Learning Media by Media
}

\author{
Valentina Dagiene and Gintautas Grigas
}

Institute of Mathematics and Informatics, Lithuania

\begin{abstract}
The use of electronic mail in learning is discussed, with the emphasis on the results of recent experience gained in Lithuania over the last several years. The public competition using electronic mail and about electronic mail was chosen as an attractive and self-motivating feature. The e-mail competitions take place since 1999 one time per year. In order to make competition more attractive, the participants are invited to play a role of experts, replying to e-mail letters from imaginary novice users of e-mail. The topics of questions were concerned with proper usage of e-mail software and letter writing culture and style. The number of participants varied in the range 73-174. About one half of them were school students. It was observed that the general level of knowledge of participants is raising up from year to year and school students are capable to compete with other participants.
\end{abstract}

Key words: competitions, distance learning, cultural learning

\section{INTRODUCTION}

The number of e-mail users is growing more than 25 percent per year, and e-mail correspondence is evolving from the free short chatty e-mail messages of technical users to the sophisticated documents used by business; being proficient at writing effective e-mail is now an essential work skill. There are now many recommendations, rules, etiquette tips and advice about politic use for improving personal e-mail style (e.g., Angel, 1993).

It is true that e-mail is often written on the fly without time for leisurely review and proofing. It is also true that if you try to improve your e-mail writing using the traditional approach of paper-based communication, you dilute the power of the e-mail medium. That's why developing an effective and timely e-mail writing style is very important for students. 
Communication is a powerful tool for encouraging learners to examine new ideas and compare them to their own existing ones. Since e-mail is one of the cheapest and most available means of communication, a fact noticed quite a long time ago e.g., Welsh, 1982, we have started using it for teaching in Lithuania's secondary schools since the middle of 1990s (Grigas, 1993). At first, e-mail was used for distance teaching of programming as well in the Lithuanian National Olympiads in Informatics and the Young Programmers' School. Gradually electronic mail became available to everyone and the teaching focus shifted from technical to cultural aspects. There was also further thinking about teaching e-mail's textual practices, and of conveying deeper and more perceptive knowledge about the use of email for effective communication.

Electronic mail, itself, can be used for such teaching. This paper describes the use of e-mail competitions to enhance students' communication skills. Dagiene (1997) describes some other approaches that have also been adopted.

\section{ELECTRONIC MAIL COMPETITION - ONE OF APPROACHES FOR IMPROVING SKILLS}

The following assumptions were taken into account in designing a program for teaching about the effective use of electronic mail:

1. Practical activities are more interesting and attractive than theoretical studies for school students, especially for those of lower grades (Papert, 1980).

2. Elements of competition stimulate the learning process.

3. In order to teach electronic mail style, two most important topics should be emphasized:

- Technical aspects and problems of electronic mail (configuration of the mail program, using an appropriate character set and encoding, work with attachments, etc.)

- Correct writing of the letter (proper formatting of the message heading, presentation of personal data, etc.)

In order to make these things more interesting to learn, a Lithuanian email competition was first organised in 1999, and continues to this day. The main aim of the competition is to teach learners a sophisticated way of using e-mail and to produce more cultivated letter writing. 


\section{THE ORGANIZING STRUCTURE OF THE ELECTRONIC MAIL COMPETITION}

\subsection{Announcement of the competition and registration of the participants}

The invitation to the competition is announced in the monthly magazine "Kompiuterija" which is concerned with computer matters. The information on the forthcoming competition, the terms of registration, and address of registration are presented. There are two reasons for such registration:

1. Organizational. The e-mail addresses of participants are needed in order to send them the tasks details which are not announced in the magazine.

2. Pedagogical. The e-mail registration message gives certain information about a participant's elementary e-mail writing skills, and provides the possibility to point out the mistakes made in the application letter by responding to it.

In regard to teaching, the second reason is far more essential.

\subsection{Duration of the competition}

One full workday (from 8 a.m. till 5 p.m.) was reserved for the first competition. However, it appeared that this time was not convenient to all participants: for some of them a more convenient time was a day while for others (those have computer at home) - early morning or evening. Therefore, next year we have prolonged the time of competition to one whole day and one whole night (from midday until midday). This doesn't mean that participants have to work on the task for the whole day and night, because a couple of hours are adequate to write down the answers. A participant may simply choose the most convenient time to work on the competition.

\subsection{Course and results of the competition}

Each participant gets four tasks via e-mail (except in the third competition, when there were three tasks) and has to e-mail the solutions to the jury prior to the closing time. During the competition the e-mails are received, and the questions related technical problems of e-mail traffic are answered. After the competition is over, all e-mail received from participants is examined and considered. The results are announced in the next issue of the magazine. The review of solutions and the correct solutions are also 
published so that those readers of the magazine who didn't take part in the competition may also learn some lessons from it.

The participants who win prizes may reclaim them in certain sections of the daily newspaper 'Lietuvos rytas' that are scattered through the country.

\section{TASKS FOR THE ELECTRONIC MAIL COMPETITION}

In order to make tasks more attractive, some game elements have been adopted. The task is presented like an e-mail message whose apparent author requests a consultation in one or other issue that is connected with electronic mail. Participants of the competition are assigned the role of an expert. They have to write a skilled and cultivated response as if they were a real expert.

\subsection{Character of tasks}

Each participant receives four messages, each containing a single question. These questions should fit (as in each competition) with the following features:

1. There is always one question concerned with the particulars of e-mail software, for example: how to choose the proper encoding of the message, what measures should be taken if some difficulties are encountered while reading the message, etc.

2. At least one question is devoted to e-mail writing etiquette, neat and cultivated writing style: a 'requester' asks how to correct language mistakes, applies for some advice about how to write a message to the serious recipient.

3. The rest of the questions usually are taken from different situations; there are always certain objectives that involve some elements of surprise or uniqueness. They work somewhat like a puzzle.

Not only a correct, clear and full reply is important, but also participants' must have the correct means of sending a message, i.e. each participant must have a computer and e-mail program with the proper settings:

1. The proper character set must be included in the header of the message and should be in correspondence with the message content encoding.

2. The right date, time, and time zone has to be in the message header.

3. In the address field From: a personal name should be given as well.

4. The registration massage has to have the same subject as it is indicated in invitation to competition. The participants have sent their answers as email replies to the questioners. 
The desired culture of e-mail correspondence is delivered in an implicit way by ensuring that participants observe these requirements. During the first two competitions these criteria were used to reduce the evaluation points if these requirements were ignored. However, while this had an influence on the final results, it was noticed later that it has a little effect on learning because participant see their mistakes after the results are announced, and forget them until the next competition.

In the third competition we have changed our tactics. We decided to enforce these rules during registration. If the rules are observed, the application is accepted and the participant receives a registration number. If not, the application is rejected and the potential participant is informed what was wrong in the message and to attempt registration once more.

In order to make registration livelier we have introduced one more type of prize - a lottery where the chances to win depends on the time of registration. During registration the participants are placed into groups of different size: the first group contains only 1 member (No. 1 ), the second -2 (No. 2 and No. 3), the third -4 (No. 4-7), the fourth -8 , and so on. There is one lucky number in each group. So those who did not succeed at registering at the first attempt have reduced chances to win the lottery, but it doesn't have any influence on the main results of competition.

\subsection{Examples of tasks}

Solutions to each and every task were given in the answers to the inquiry letters. For example, during one competition, four persons - Jonas Jonaitis, Petras Petraitis, Povilas Povilaitis and Jurga Juragaitè - wrote inquiring letters. Of course these persons were not real. Their names were made-up in order that the participants of the competition could better empathize with the expert's role and could more naturally show the cultivated communication via e-mail with the particular, but unfamiliar person who is seeking the advice.

The questions were chosen so that the competition participants could have as equal a starting position as possible, irrespective of the operating system or mail program used by them. 


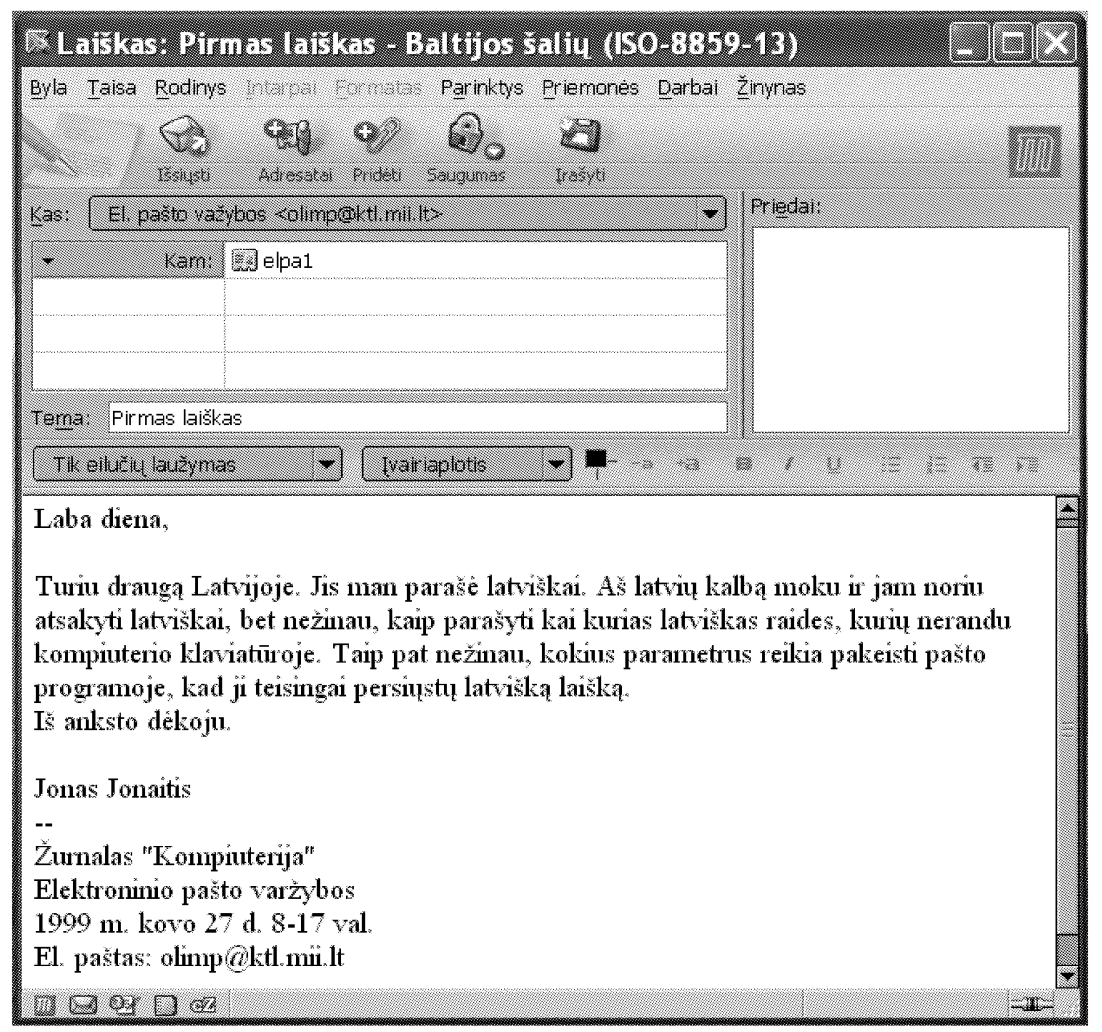

Figure 1. The first message to the participants of the first competition (translation below)

'Hello, I have a friend from Latvia. He wrote me a message in Latvian. I know the Latvian language and would like to answer him in Latvian but I have no idea how to type some Latvian letters, which are not on the keyboard. Also I don't know which parameters in the mail program have to be changed that the letter in Latvian could be sent correctly. Thank you in advance. Jonas Jonaitis'

The third message to the participants of the first competition was: 'Hello, I have got the warning message to be warty of an e-mail with the title "VVV" in the subject field. It was also written that if I try to read that message my computer will get infected with a dangerous virus. I would like to ask, and get a reasoned explanation, whether it is really possible to infect a computer via e-mail. Sincerely, Povilas Povilaitis' 


\section{PARTICIPANTS}

Each year there were many participants (Fig. 2).

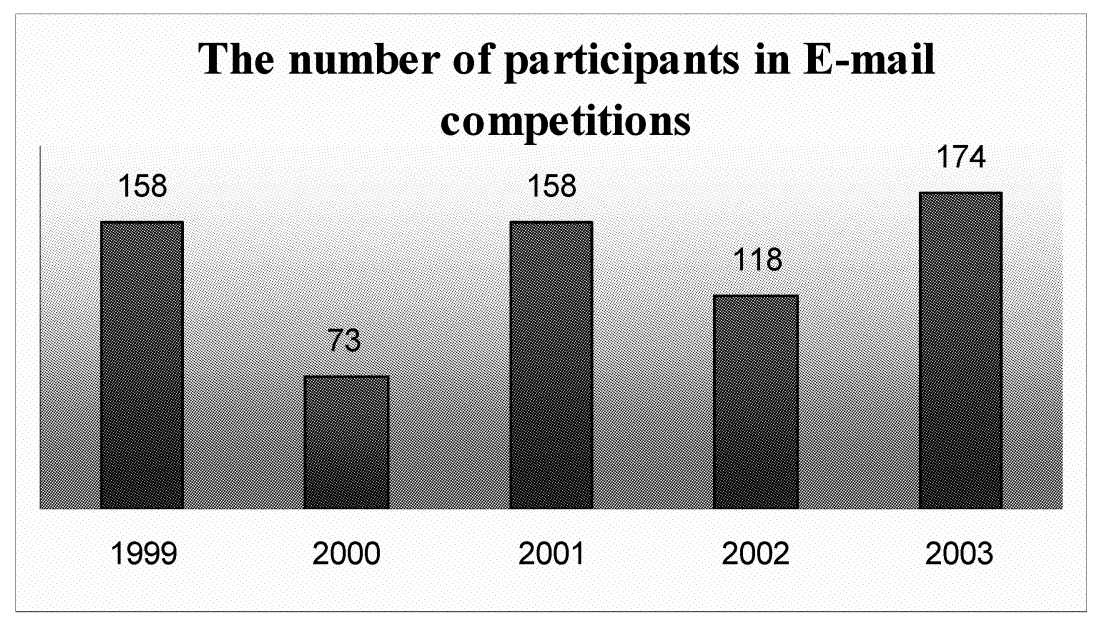

Figure 2. Number of participants in the e-mail competitions

The winners of the first two places in the first competition have received quite precious prizes, CD players, while the winners of other places were received only souvenir gifts. In the later competitions there were only souvenir gifts. However, the number of participants didn't decrease.

Anyone may take part in the competition. Approximately half of the participants were school students. Organizers of the first competition were afraid that school students could have difficulties competing with the professionals (for example, with the mail administrators). Therefore the competition rules had a warranty saying that one of the first two prizes should be given to a school student, i.e., the best school student should win at least the second place. However, it happened that the school students scored enough points to win the first prize. The second place was given to a teacher and the other eight places were equally distributed among school students and other participants. Therefore, in the next competition, there weren't any privileges for the school students.

This was not a major issue-our aim was to raise the e-mailing culture in all spheres, and the privileges that in the beginning were given to the school students have been given simply to encourage them to participate in the competition. 


\section{CONCLUSIONS}

Deeper understanding of electronic e-mail is highly important to the language and culture of our country. It's a tool that helps to pay attention on the questions of proper adaptation of the mail programs in the cultural environment. The elements of electronic culture have to be taught using different methods. Electronic mail is one of the most convenient and most often used tool of information technology.

In comparing the results of the competitions, we see that the general level of the participants' skills is rising. The general level of school students skills does not differ much from those experts of informatics.

The price of prizes doesn't have an observable influence on the number of participants. Participants are more interested in the content of competition, then in a prize. It's clear from the messages of participants that they far more enjoy enjoy being in the expert's shoes than in the pupil's who has to give his answers to the teacher or jury member.

The sharp-witted answers of the experts give a pleasure to jury members and encourage them to organize e-mail competitions in future.

\section{REFERENCES}

Angel, D., \& Heslop, B. (1993). The Elements of E-mail Style. New York: Addison-Wesley. Dagiene, V. (1997, Dec. 2-4)). Learning via Electronic Mail: What and How? Paper presented at the Education for the 21st Century conference, Cape Town, South Africa.

Grigas G. (1993). An experiment of computer programming practice by e-mail. Interpersonal Computing and Technology, 1(2), 1-10.

Papert, S. Mindstorms: Children, Computers, and Powerful Ideas. Basic Books. N. Y., 1980.

Welsh, L. A. (1982). Using Electronic Mail as a Teaching Tool. Communications of the ACM, 23(2), 102-108.

\section{BIOGRAPHY}

Valentina Dagiene is the head of the Department of Informatics Methodology at the Institute of Mathematics and Informatics as well as an Associate Professor at the Vilnius University. She has published over 80 scientific papers and the same number of methodical works, has written more than 30 textbooks in the field of informatics for high school. Her main research focus is teaching informatics and information technologies in primary, basic, and secondary school, localization of software, teaching Logo, problem solving.

Gintautas Grigas is senior research worker of the Department of Informatics Methodology at the Institute of Mathematics and Informatics. He has published over one hundred scientific papers, about the same number of popular articles, and 32 books in the field of programming 
and teaching of programming. His main current research focus is Internet software localization. 